\title{
On Single-Edge-Crack Tension Specimens for Tension-Compression Fatigue Crack Growth Testing
}

\author{
Ashok Saxena ${ }^{1}$, Federico Bassi ${ }^{2}$, Kevin Nibur ${ }^{3}$ and James C. Newman, $\mathrm{Jr}^{4}$ \\ ${ }^{1}$ Corresponding Author, University of Arkansas, Fayetteville, AR, 72701 \\ ${ }^{2}$ Politecnico di Milano, Milano, 20156, Italy \\ ${ }^{3}$ Hy Performance Materials Testing LLC, Bend, OR, 97701 \\ ${ }^{4}$ Mississippi State University, Mississippi State, MS, 39762
}

\begin{abstract}
Single-edge-crack (SEC) specimens with rigid threaded ends are well suited for fatigue crack growth testing in extreme environments and for conducting tests at negative load ratios. Stress intensity parameter, $K$, and crack mouth opening displacement, CMOD, solutions as a function of crack size for this geometry are derived using 3-D finite element analyses using multiple codes. Both $K$ and CMOD values obtained are shown to be comparable between the various finite element codes used. The solutions are sensitive to the height $(2 H)$ to width $(W)$ ratio of the specimen, as well as to the aggregate bending stiffness of the members of the loading train. A procedure utilizing the computational results for various $2 H / W$ values and a set of specially designed fatigue crack growth experiments is described to develop custom solutions for estimating $\mathrm{K}$ and CMOD values that account for both, the $2 \mathrm{H} / \mathrm{W}$ ratio and the bending stiffness of the loading train.
\end{abstract}

Key words SEC(T), K-calibration, CMOD, 3D Finite element, Fatigue Crack Growth

\section{Introduction}

Single-edge-crack (SEC) specimens are commonly used to generate fatigue-crack growth and fracture properties of metallic materials. The overall shape of the SEC specimen, as compared to compact, $\mathrm{C}(\mathrm{T})$, specimens, is much better suited for crack growth testing in extreme environments where the specimen is contained in an autoclave or an environmental chamber. Further, the possibility of gripping the specimen rigidly on the ends makes SEC specimen attractive for tension-compression load testing for which $\mathrm{C}(\mathrm{T})$ specimens are not suitable.

Expressions for estimating stress-intensity factor, $K$, and crack-mouth-opening displacement, CMOD, for SEC specimens have been available in the literature [1] for some time. However, in the case of rigidly gripped single-edge-notch tension, SEC(T), specimen, the $\mathrm{K}$ and CMOD values at various crack sizes are also a function of the specimen gage length and the stiffness characteristics of the loading train. No widely accepted $K$ and CMOD solutions are available for these conditions which must be customized for the situation at hand.

In this paper, FEM analysis is used to determine the stress intensity parameter, $K$, and the crack mouth opening displacement (CMOD) relationships as a function of crack size for SEC(T) specimens that are rigidly gripped on the ends. The dependence of K-solutions on the gage length of the specimen is extensively explored in these calculations. However, there are no analytical or computational techniques capable of accounting for the stiffness of the loading train on the $K$ solutions for rigidly gripped SEC(T) specimens. Loading trains can be quite long, and therefore 
compliant, for specimens tested in environmental chambers and can add significantly to the effective gage length of the specimen in the estimation of K and CMOD values. An experimental procedure was devised for choosing the most appropriate effective gage length for accurately estimating $\mathrm{K}$ and CMOD versus crack size in SEC(T) specimens that is specific to the test set up.

\section{Finite Element Analysis}

Figure 1 shows the drawing of the specimen analyzed in this study. Finite element analysis code ABAQUS [2] was used to develop the stress-intensity factor, $K$, and crack-mouth-opening displacement (CMOD) as a function of crack size, $a$, to width, $\mathrm{W},(a / W)$ ratio. Analyses were carried out for several $H / W$ values and polynomial equations were developed to fit the analysis results.

Two dimensional quadratic plane strain elements model and a three dimensional 8-node linear brick elements model were used in the analyses carried out using the ABAQUS code. Because of the symmetry, only one half of the specimen was analyzed in 2D simulations and for the 3D simulations, only quarter of the specimen was analyzed as shown in Fig. 2.

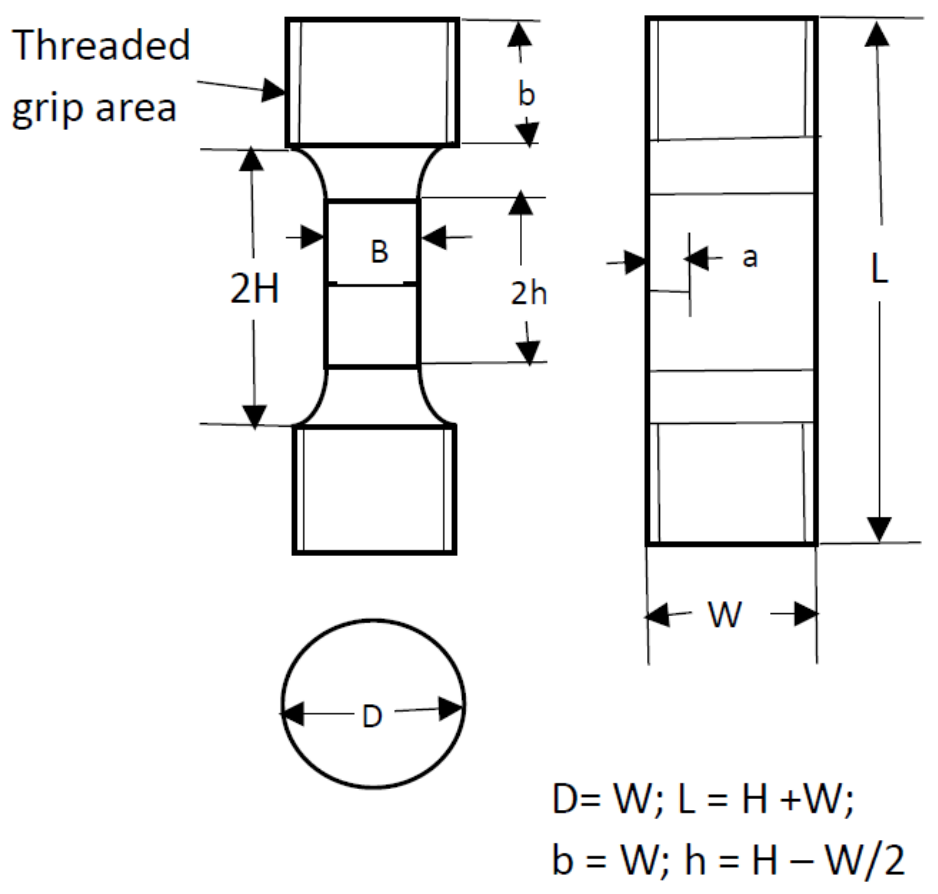

Fig. 1- The geometry and dimensions of the single-edge-notch-tension, SEC(T), specimen analyzed.

The 3D model included the threaded section of the specimen in which $b=W$. Figure 3 shows the mesh used for the simulations. Around the crack-tip, a semi-circular shaped mesh with an average element size of $0.02 \mathrm{~mm}$ was used that facilitates the estimation of the J-integral values. In the 
quadratic plane strain mesh, a mid-node collapse at $1 / 3$ of the element length was used because it is known to decrease the numerical singularities associated with cracks.

The 2D model was subjected to a displacement $u$ at a reference point located on the upper surface of Fig. 2. The prescribed displacement was constant on the entire upper surface of the model to realistically represent how the specimens are actually gripped via threads not allowing any rotations. The 3D model was loaded with a uniform displacement applied to the entire threaded section. A symmetry boundary condition along the ligament surface was applied to both models as shown in red in Fig. 2. One 2D simulation was performed by considering only the gage length $2 h$ of the specimen shown in Fig. 2 with full freedom of rotation. This is equivalent to the case of a pin loaded SEC specimen or a case of infinite specimen length.

Two other finite-element codes WARP3D [3] and ZIP3D [4], were also used to generate $K$ and CMOD solutions for comparing with the ABAQUS results. The mesh generator code in ABAQUS [2], was used to generate the three-dimensional mesh for the SEC(T) configuration, as shown in Figure 4. The one-quarter model had 109,999 nodes and 98,926 elements (8-noded isoparametric). The back-face of the model had center plane boundary conditions (normal displacement was zero; and no shear stress). The exterior nodes around the threaded section were displaced in the direction perpendicular to the crack plane, and fixed in the other orthogonal directions. Nodes along the crack plane were stress free, and the other nodes across the net-section had symmetry boundary conditions. The stress-intensity factor was calculated from local domain integrals in the WARP3D code, and both WARP3D and ZIP3D used global energy to calculate the stress-intensity factor assuming plane-stress conditions. The CMOD was calculated as the average value from the 11 nodes at the crack mouth.
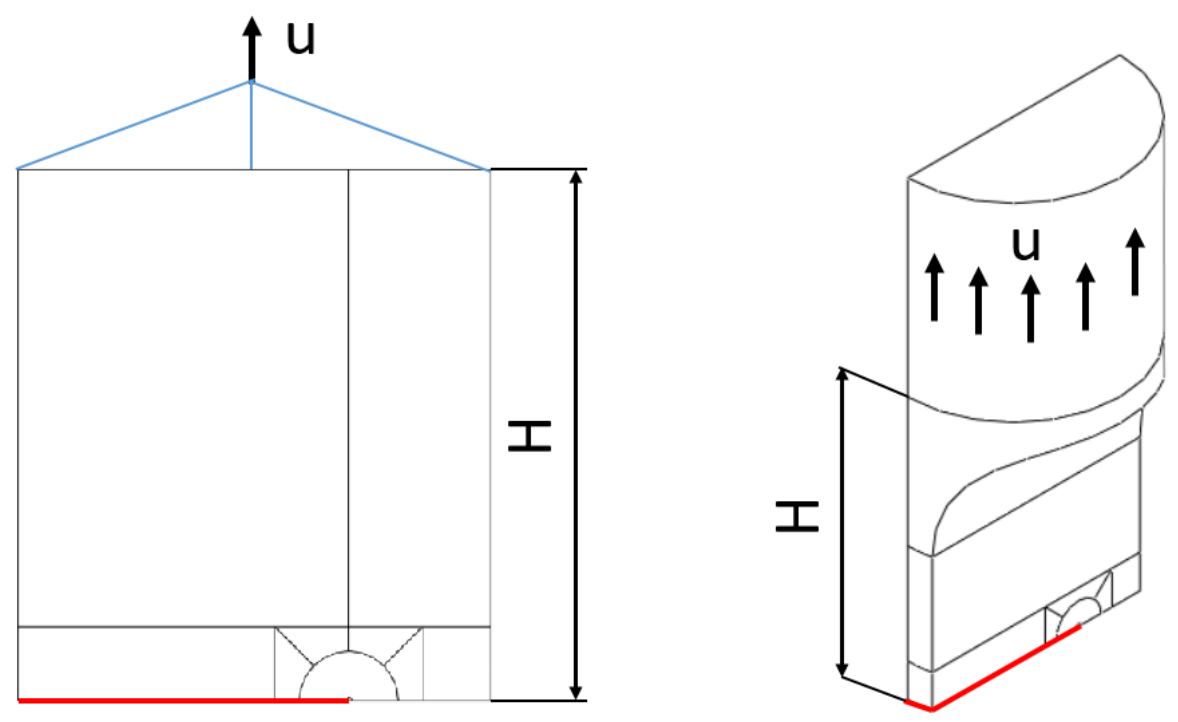

Fig. 2- 2D (left) and 3D (right) FE models of the SEN(T) specimens. 


\section{Results and Discussion}

Simulations were first performed for a $2 H / W$ value of 2.25 . The J-integral values were obtained from the $25^{\text {th }}$ available contour that provided a stable path-independent value. The applied force $P$ was calculated as the resultant force at the reference point. The $\mathrm{K}$ is given by equation (1).

$$
K=\frac{P}{B W} \sqrt{\pi a} f(a / W)
$$

The function $f(a / W)$ trends to converge to the value of 1.12 i.e. the solution of a semi-infinite plate under uniform tension containing a small crack, as $a / W$ approaches zero. It is also seen that the 2D model with the constraint of uniform displacements on the top surface yields similar values to the $3 \mathrm{D}$ analysis. However, when free rotation is allowed, the $f(a / W)$ values are significantly higher as seen in Fig. 5. Thus, $2 \mathrm{H} / \mathrm{W}$ is also expected to play a significant role in determining the value of the K-calibration function, $f$, and deserves further exploration. Figure 6 shows a comparison between results from ABAQUS and from WARP3D and ZIP3D codes showing very comparable results for both the K-calibration function and the non-dimensional compliance represented by $\frac{B E V}{P}$ where, $V=\mathrm{CMOD}$ and $E=$ elastic modulus.

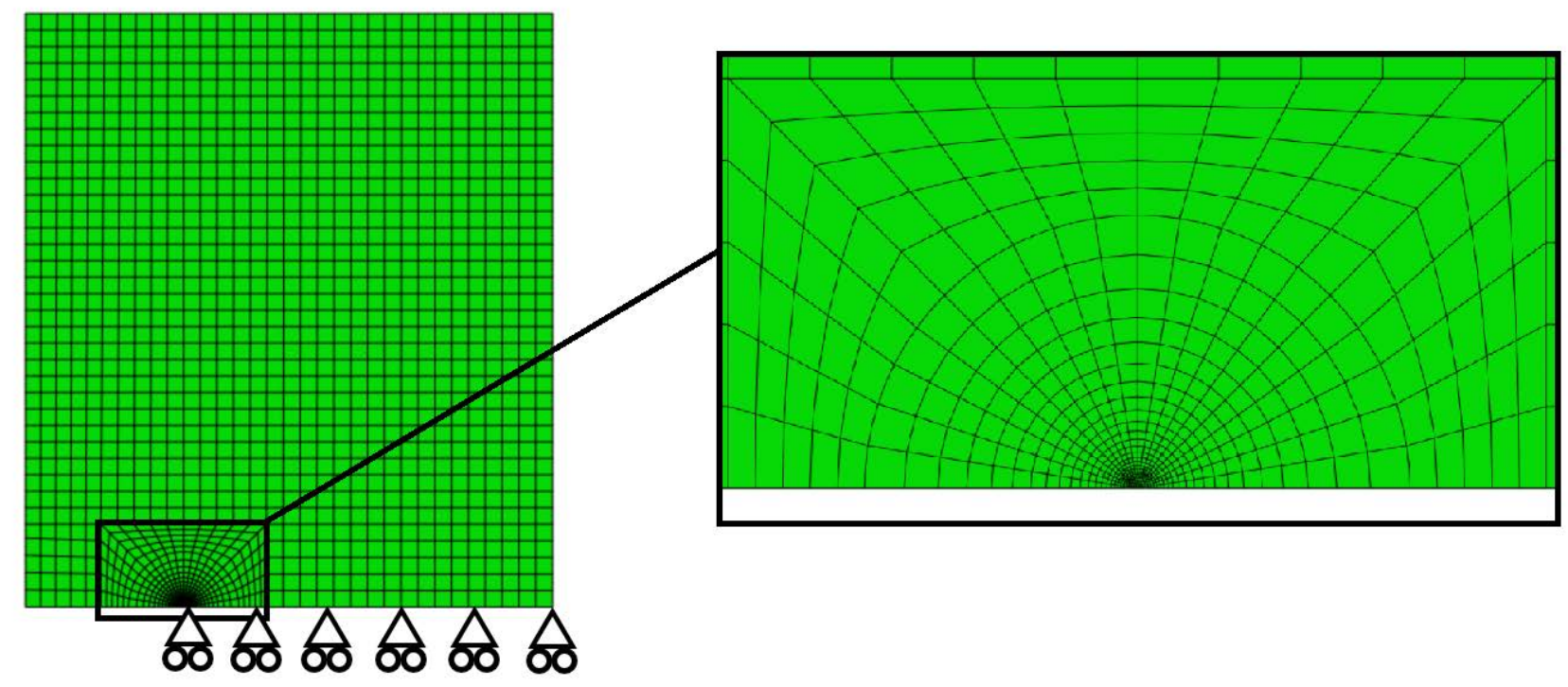

Fig. 3- Finite element model for the SEN(T) specimens.
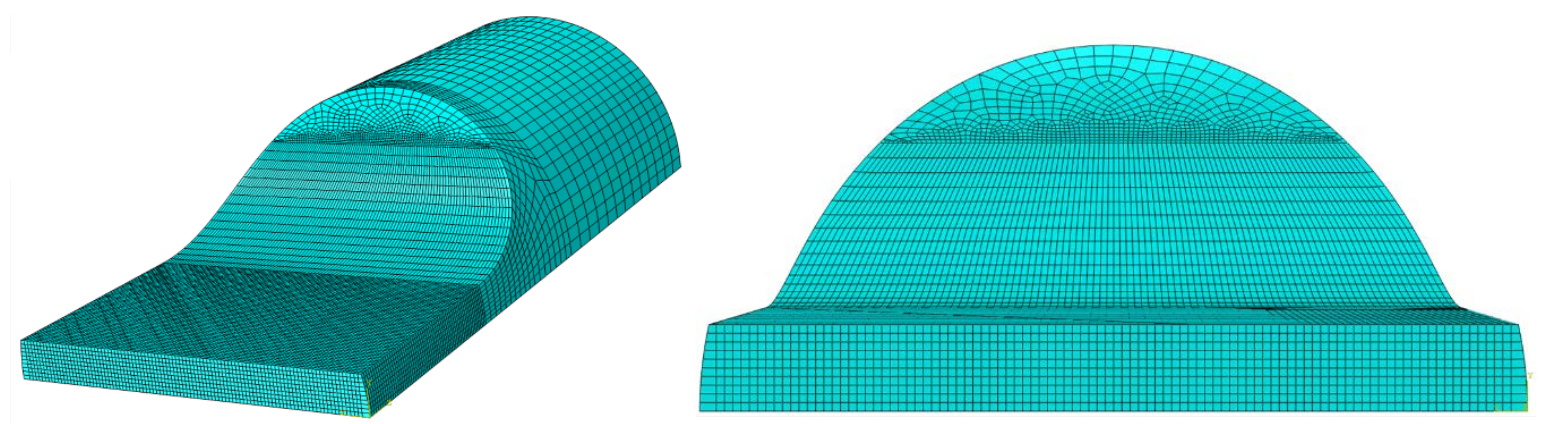

Figure 4 - Finite-element one-quarter model of SEN(T) specimen in the WARP3D code (a) One-quarter model and (b) Crack-plane view. 
The analysis for estimating the K- calibration function was repeated for $2 \mathrm{H} / \mathrm{W}$ values of $1,1.25,2$, and 5 and the results are compared to the values of 2.25 in Fig.7. It is noted that for $2 H / W$ values less than 2, the $f(a / W)$ values were less than 1.12 as $a / W$ approaches zero. This is an indication that the stress field at the end of the gage length is not uniform. The counter bending moment generated on the crack plane by the rigid grips must produce non-uniform stress fields near the ends of the specimen. This was examined and shown to be the case of $2 H / W$ values less than 2 . For higher $2 H / W$ of 5 , it is seen that $f(a / W)$ function tends towards the solution obtained for the case of free rotation but is still significantly below that solution, indicating that the effects of rigid grips are still quite relevant in determining the K-solution even at that high a value of $2 H / W$.

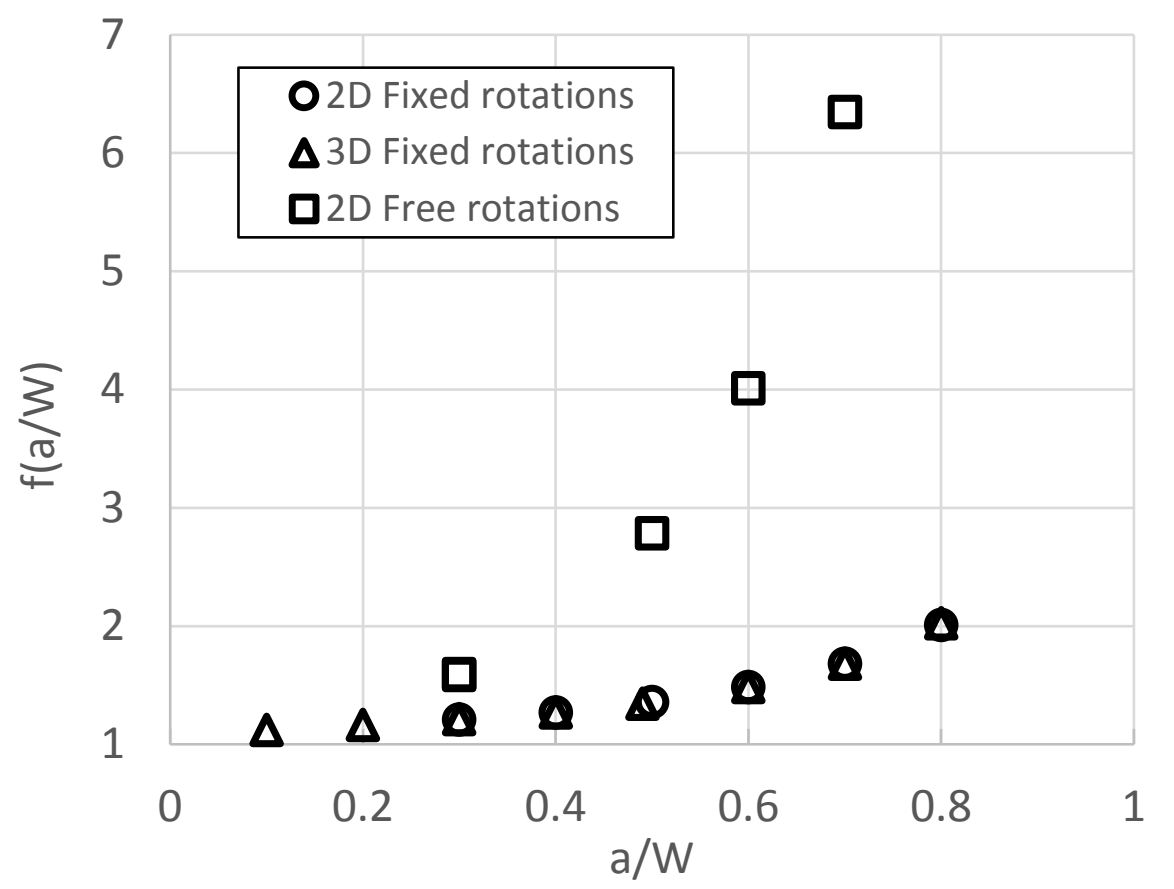

Fig. 5- The K-calibration function $f$ as a function of the normalized crack size for a $2 \mathrm{H} / \mathrm{W}$ value of 2.25.
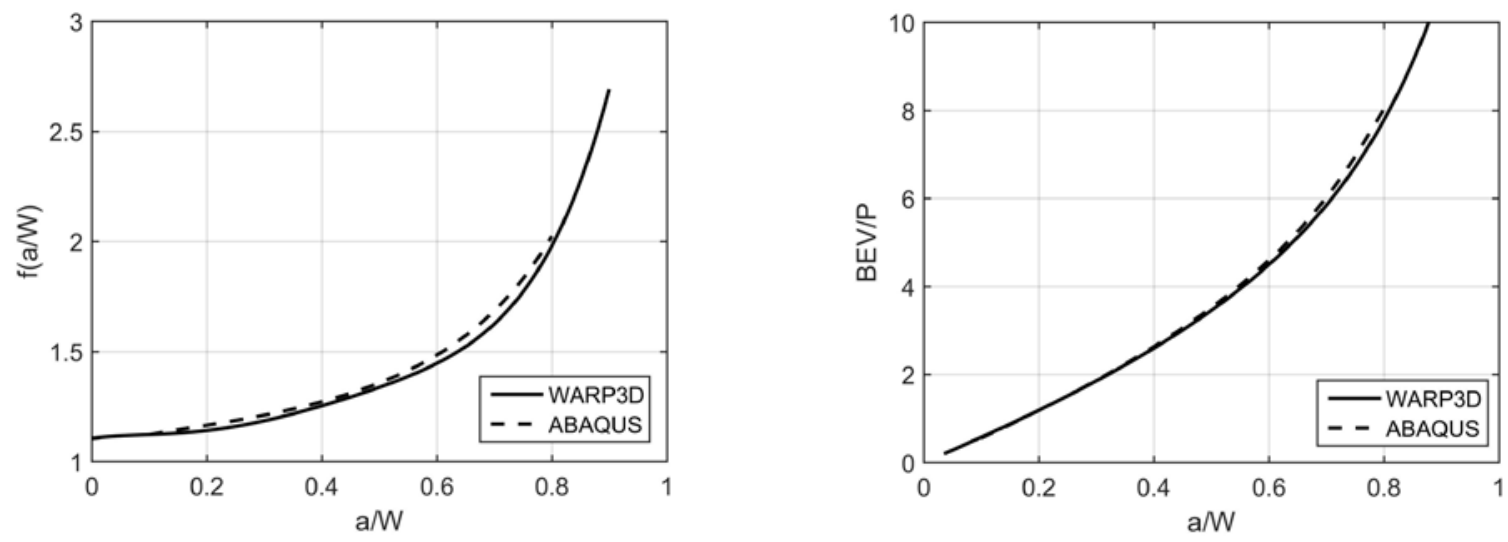

Fig. 6- Comparison of FE results (a) K- calibration function and (b) dimensionless compliance obtained from the ABAQUS and WARP3D codes for $2 H / W=2.25$. 
A $5^{\text {th }}$ order polynomial expression was fitted to the $f(a / W)$ values as a function of $a / W$ as per Eq. (2) using the least squares minimization technique. The results of the fits are represented by the solid lines of Fig. 7 and the coefficients are reported in Table 1.

$$
f\left(\frac{a}{W}\right)=c_{0}+c_{1}\left(\frac{a}{W}\right)+c_{2}\left(\frac{a}{W}\right)^{2}+c_{3}\left(\frac{a}{W}\right)^{3}+c_{4}\left(\frac{a}{W}\right)^{4}+c_{5}\left(\frac{\mathrm{a}}{\mathrm{W}}\right)^{5}
$$

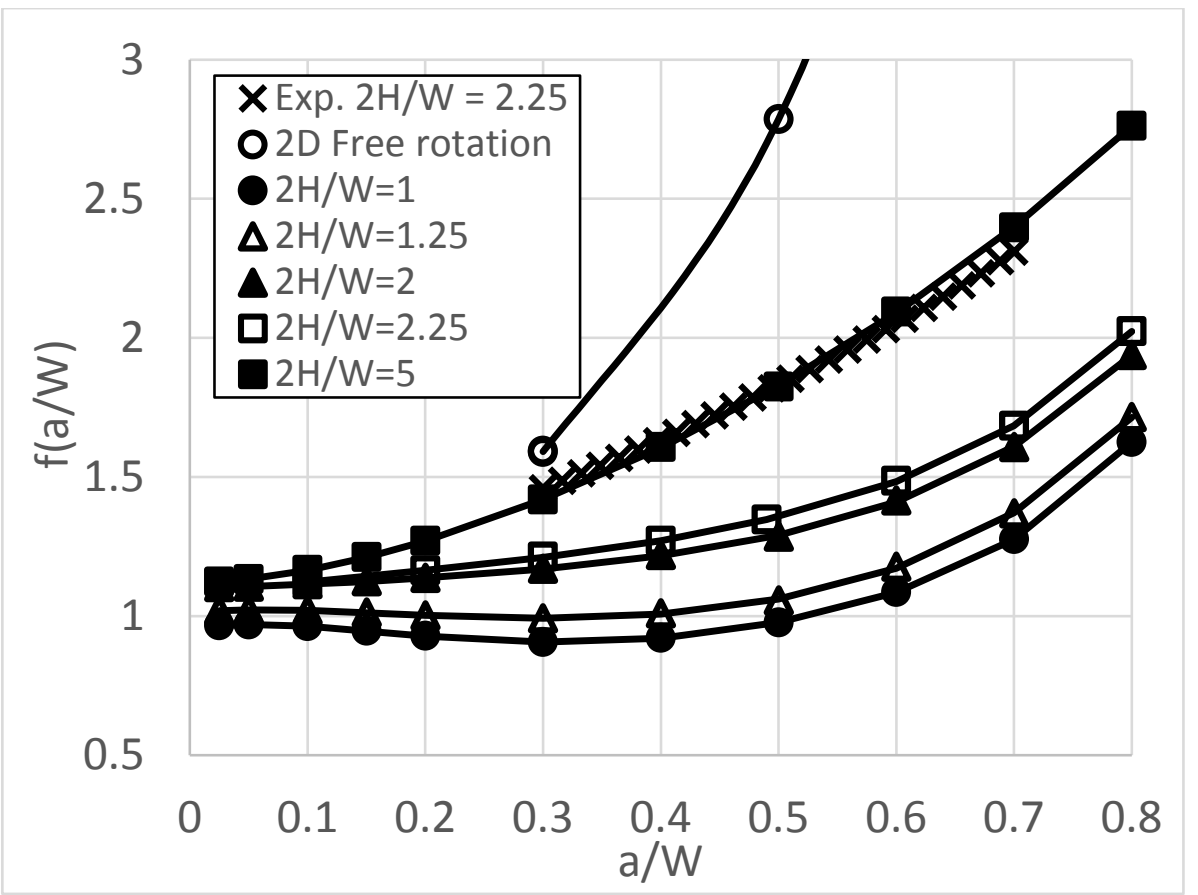

Figure 7: K-calibration function $f(a / W)$ as a function of the crack size $a / W$ at different $2 H / W$ values.

Table 1- K-calibration function, $f(a / W)$ coefficients for various $2 \mathrm{H} / \mathrm{W}$ ratios

\begin{tabular}{|c|c|c|c|c|c|c|c|}
\hline & \multicolumn{5}{|c|}{$2 H / W$} & \multirow{3}{*}{$\begin{array}{c}\text { Experimental } \\
2 \mathrm{H} / \mathrm{W}=2.25 \\
0.3 \leq \mathrm{a} / \mathrm{W} \leq 0.8\end{array}$} & \multirow{3}{*}{$\begin{array}{l}\text { Free rotation } \\
0.2 \leq \mathrm{a} / \mathrm{W} \leq 0.8\end{array}$} \\
\hline & 1 & 1.25 & 2 & 2.25 & 5 & & \\
\hline & \multicolumn{5}{|c|}{$0.05 \leq \mathrm{a} / \mathrm{W} \leq 0.8$} & & \\
\hline$c_{0}$ & 0.9549 & 1.0127 & 1.0995 & 1.0553 & 1.1176 & 1.0925 & -0.8293 \\
\hline$C_{1}$ & 0.6182 & 0.3627 & 0.1199 & 0.9344 & 0.1297 & 1.1621 & 11.4687 \\
\hline$c_{2}$ & -7.43 & -3.9499 & 0.2314 & -3.6235 & 3.8146 & -1.9445 & -11.0016 \\
\hline$c_{3}$ & 23.8337 & 11.8806 & 0.7682 & 11.0514 & -3.9246 & 11.6215 & -6.487 \\
\hline C4 & -30.5202 & -14.0839 & -1.7991 & -14.6547 & 3.2687 & -17.905 & 10.3003 \\
\hline$C_{5}$ & 15.9583 & 8.0116 & 2.8637 & 8.8003 & -0.7024 & 9.9359 & 25.5383 \\
\hline
\end{tabular}

Elastic compliance, $C=V / P$, was estimated from the FE results at each crack size and for all $2 \mathrm{H} / \mathrm{W}$ values analyzed where, $V=$ half of the crack mouth opening displacement obtained as the displacement at the crack mouth $0.065 \mathrm{~W}$ above the crack plane as shown in Fig.8. Normalized 
compliance, $E^{\prime} B C$ (where, $E$ ' is the elastic modulus, $E$, for plane stress and $\frac{E}{\left(1-v^{2}\right)}$ for plane strain) was subsequently calculated for each crack size and $2 H / W$ value and converted to the variable, $u$, defined in equation (3) [5]. The variable $u$ was then used for deriving polynomial fits relating dimensionless compliance to normalized crack size as described in equation (4).

$$
\begin{gathered}
u=\frac{1}{\sqrt{\left(E^{\prime} B C\right)}+1} \\
\left(\frac{a}{W}\right)=b_{0}+b_{1}(u)+b_{2}(u)^{2}+b_{3}(u)^{3}+b_{4}(u)^{4}+b_{5}(u)^{5}
\end{gathered}
$$

The results of the numerical simulations and the regression fits for determining the coefficients, $b_{i}$ are shown in Fig. 9 and listed in Table 2.

These results for estimating $\mathrm{K}$ and CMOD in rigidly gripped SEC(T) specimens are useful for testing in air environment when the daylight between grips is truly $2 \mathrm{H}$ because the fixtures are very stiff and short and further the lateral displacement in the hydraulic actuator can be constrained. This is not possible while testing in extreme environments such as in high pressure hydrogen or at high temperatures, because the actuator length has to increase to accommodate the environmental chamber. In these circumstances, and effective $2 \mathrm{H} / \mathrm{W}$ value must be determined experimentally as described below.

A custom K solution can be generated for the SEC(T) specimen that accounts for the bending stiffness of the loading train. As an example, a specimen that was tested in a high pressure hydrogen cell is used to illustrate the method used. Two SEC(T) specimens with the following dimensions referred to Fig. 1 were tested under conditions of nominally constant delta K over the crack size range of $0.37 \leq a / W \leq 0.8 . B=4 \mathrm{~mm}, W=19.05 \mathrm{~mm}, 2 h=23.8 \mathrm{~mm}, 2 H=42.86 \mathrm{~mm}$, $b=19.05 \mathrm{~mm}, 2 L=81 \mathrm{~mm}$.

The target $\Delta K$ for the two specimens was 15 and $25 M P a \sqrt{m}$ based on an assumed approximate $K$-solution because the correct $K$ solution had not yet been determined. The actual average $\Delta K$ for these two tests was later estimated to be 17.6 and $34.4 \mathrm{MPa} \sqrt{\mathrm{m}}$, respectively. Compact, C(T), specimens with very well established $K$-solutions were then used to determine the Paris law relationship in air at a load ratio, $\mathrm{R}=0.2$ and that relationship is given in equation (5).

$$
\frac{d a}{d N}=4.941 \times 10^{-9}(\Delta K)^{3.064}
$$

Where, $\frac{d a}{d N}$ is in $m m / c y c l e$ and $\Delta K$ is in $M P a \sqrt{m}$

Combining equations (1) and (5), we can derive the following relationship:

$$
f\left(\frac{a}{W}\right)=\frac{B W}{P} \frac{1}{\sqrt{\pi a}}\left(\frac{1}{4.941 \times 10^{-9}} \frac{d a}{d N}\right)^{1 / 3.064}
$$

The SEN(T) K-solution was then estimated using the data from the two SEC(T) specimens over the crack size range given by $0.3 \leq a / W \leq 0.8$, which is the range over which the fatigue crack 
growth rate experiments were conducted. In equation (6), size of the specimen is known, $d a / d N$ was measured, and the load at each crack size was recorded; subsequently, $f(a / W)$ was estimated at each crack size from equation (6) and all the data were curve fitted with a $5^{\text {th }}$ order polynomial that yielded coefficients listed in Table 1. A comparison of the crack growth rate data from C(T) specimens and from SEC(T) specimens using the corrected K-solution are plotted in Fig. 10. These data clearly show that the corrected K-solution generated from the experimental results yield fatigue crack growth rate results that are very comparable to the results from the more established $\mathrm{C}(\mathrm{T})$ specimens.

It must be noted that the solution above is specific only to the specimen of the size dimensions used in this experimental set up mounted on the particular grips and fixtures used to test in the experiments conducted. However, the approach can be used to derive K-solutions for specimens of other sizes and/or test configurations.

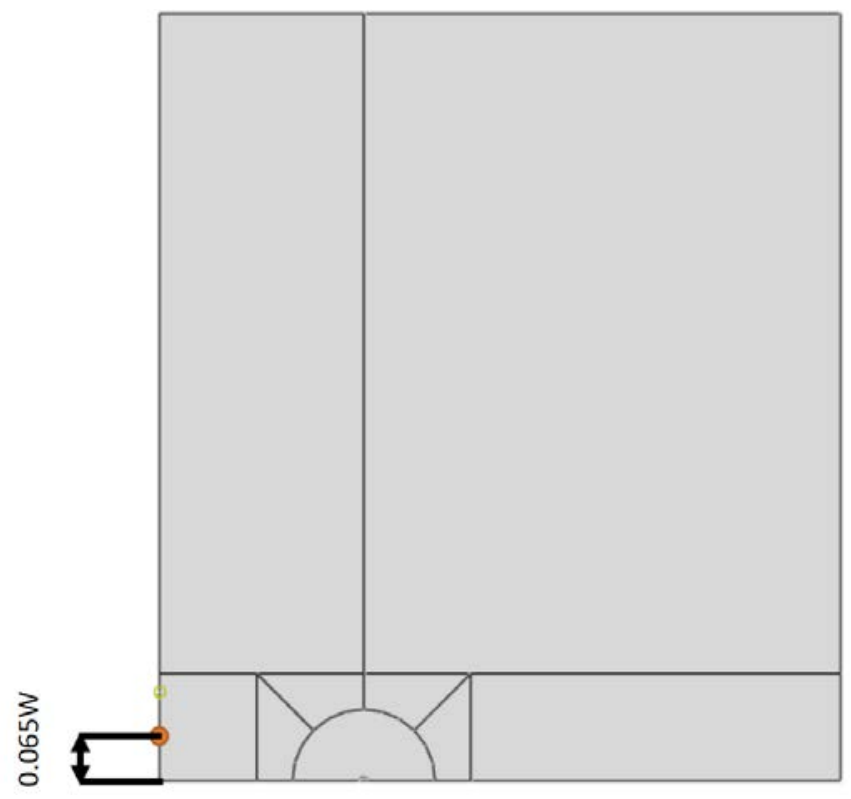

Fig. 8- Schematic showing the points across which CMOD was calculated.

It should be noted that this solution is close to one for $2 \mathrm{H} / \mathrm{W}$ value of 5 even though the $2 \mathrm{H} / \mathrm{W}$ for this geometry was 2.25 . This result is likely explained by the presence of the long and relatively skinny load train used to apply force to the specimen while it was installed inside the pressure vessel.

\section{Summary and Conclusions}

Single-edge-notch-tension, SEC(T) specimens with threaded ends are analyzed using 3-D finite element codes to estimate the stress intensity parameter, $K$, and crack mouth opening displacement, CMOD, solutions as a function of crack size. Fatigue crack growth rate tests were performed on 
SEC(T) and compact type, C(T), specimens to correct the $K$-solutions for height to width ratio dependency and for the bending stiffness of the loading train. This work yielded custom $K$ and CMOD solutions that can be used for testing in extreme environments. Following conclusions are derived from this work.

- Both $K$ and CMOD values obtained are shown to be comparable between the various codes used.

- The solutions are sensitive to the height $(2 H)$ to width $(W)$ ratio of the specimen, as well as to the bending stiffness of the members of the loading train.

- A procedure utilizing the computational results for various $2 H / W$ values and a set of specially designed experiments is described to develop custom solutions for estimating $K$ and CMOD values.

- The K-solutions for a specimen with an $2 \mathrm{H} / \mathrm{W}$ ratio of 2.25 corrected for bending stiffness behaved like a specimen with a $2 \mathrm{H} / \mathrm{W}$ ratio of 5.0.

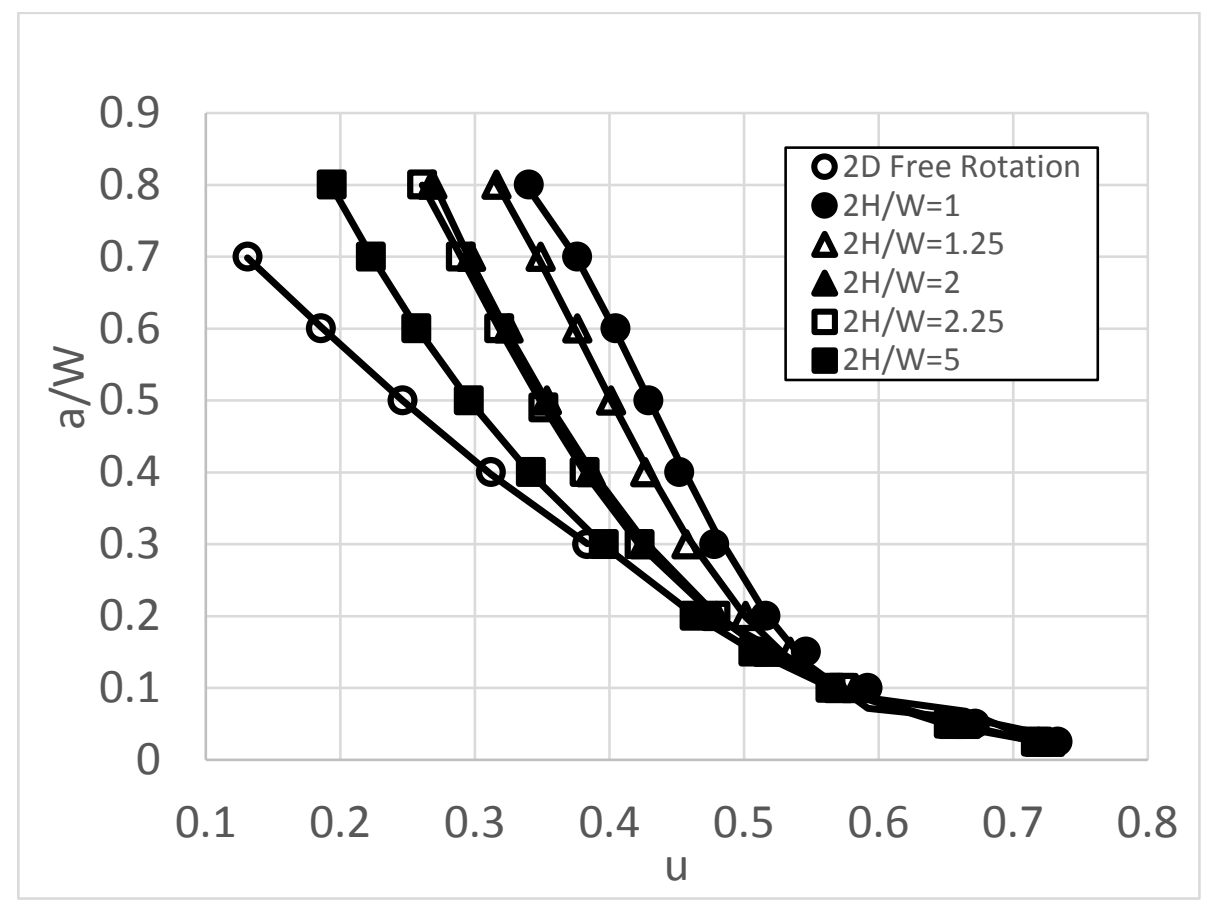

Figure 9- Normalized crack length as a function of the normalized elastic compliance. The symbols denote FE calculated values and lines represent the fits to equation (4) 
Table 2: Elastic compliance coefficients for various $2 H / W$ values.

\begin{tabular}{|c|c|c|c|c|c|c|}
\hline \multicolumn{6}{|c|}{$2 \mathrm{H} / \mathrm{W}$} & \multirow{2}{*}{$\begin{array}{c}\text { Free } \\
\text { rotation }\end{array}$} \\
\hline & 1 & 1.25 & 2 & 2.25 & 5 & \\
\hline$b_{0}$ & -5.9673 & -1.7433 & 2.1473 & 0.563258 & 1.7127 & 0.9356 \\
\hline$b_{1}$ & 57.8796 & 28.1333 & -5.3424 & 9.238349 & -6.1742 & -1.8212 \\
\hline$b_{2}$ & -161.724 & -93.9295 & -1.027 & -48.4931 & 8.3829 & -0.0304 \\
\hline$b_{3}$ & 147.6862 & 99.0292 & 9.0465 & 65.58862 & -4.7041 & 0.7065 \\
\hline$b_{4}$ & 19.3236 & 3.7629 & 0.076 & 1.858554 & -0.0798 & 0.9228 \\
\hline$b_{5}$ & -62.7395 & -40.1236 & -5.9002 & -38.4394 & 0.9788 & 0.9803 \\
\hline
\end{tabular}

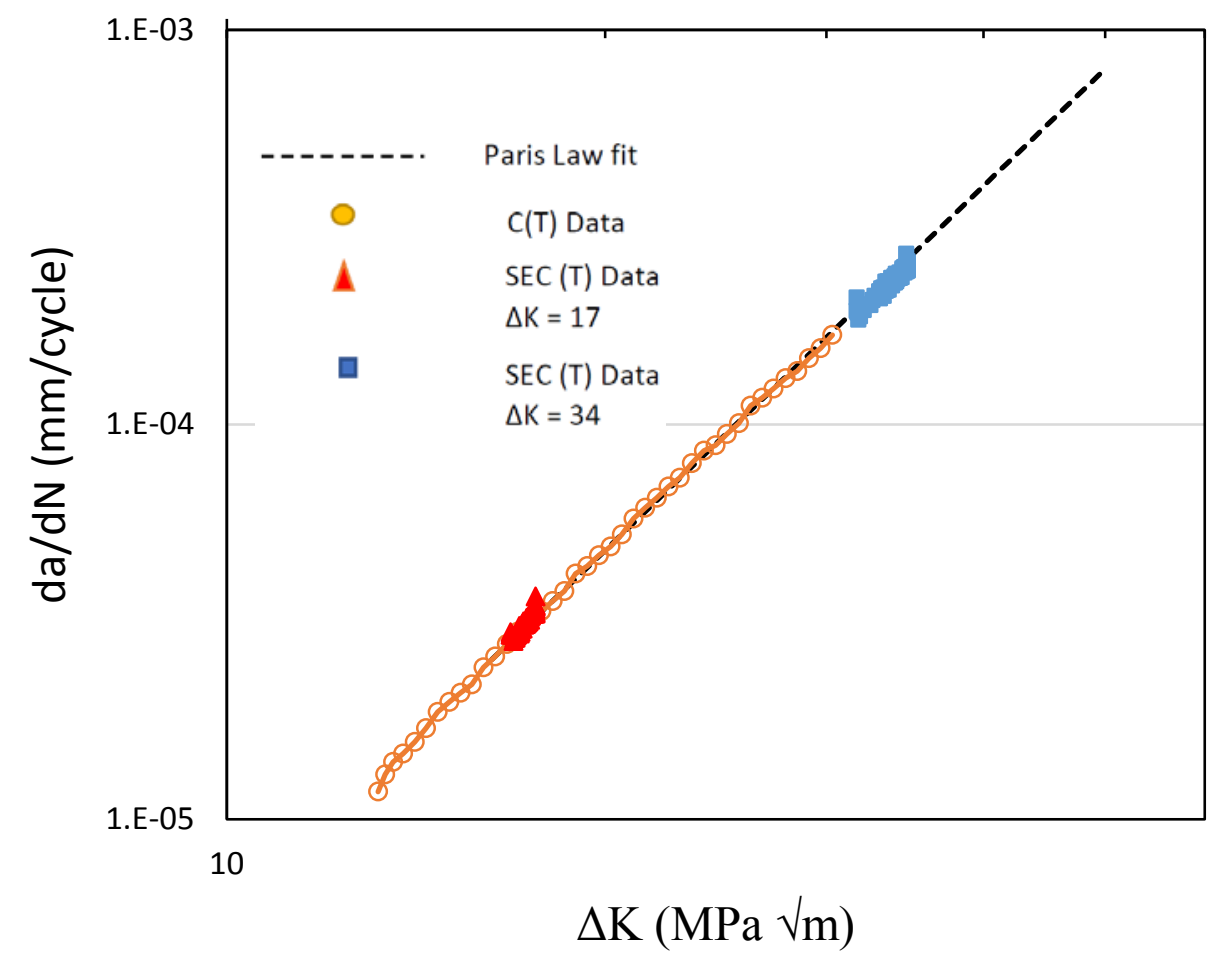

Figure 10- Comparison of FCGR data from SEC(T) specimens and C(T) specimens showing that both specimens yield identical FCGR results.

\section{Acknowledgements}

The partial financial support of the Department of Energy through their Office of Energy Efficiency and Renewable Energy (EERE) for this work through a contract to Wiretough Cylinders, LLC is gratefully acknowledged. In particular, we acknowledge the direction of Dr. 
Amit Prakash of Wiretough Cylinders, LLC, Dr. Katie Randolph, Project Manager, Neha Rustagi, Co-Project Manager, and Erika Gupta of EERE.

\section{Nomenclature}

$\begin{array}{ll}a & \text { crack length } \\ \text { B } & \text { specimen thickness } \\ W & \text { specimen width } \\ E & \text { modulus of elasticity } \\ f(a / W) & \text { boundary-correction factor } \\ K & \text { stress-intensity factor } \\ P & \text { applied load } \\ V & \text { crack-mouth-opening displacement } \\ a / W & \text { crack-length-to-width ratio } \\ (E B V / P) & \text { dimensionless compliance }\end{array}$

\section{References}

1. H. Tada, Paul C. Paris and George R. Irwin, The Stress Analysis of Cracks Handbook, $3^{\text {rd }}$ Edition, The American Society of Mechanical Engineers, 2000, 675 pages.

2. ABAQUS Unified FEA. http://www.3ds.com/products/simulia/portfolio/abaqus/overview/. 2016.

3. WARP3D—Open Source Code for 3D Nonlinear Analysis of Solids, March 2016.

4. K.N. Shivakumar and J.C. Newman, Jr. "ZIP3D - An Elastic and Elastic-Plastic Finite-Element Analysis Program for Cracked Bodies,” NASA TM-102753. November 1990.

5. A. Saxena and S.J. Hudak, Jr., "Review and Extension of Compliance Information for Common Crack Growth Specimens”, International Journal of Fracture, Vol. 14, 1978, pp 453468. 